\title{
The Effect of Cerebral Ventricular Injection Extract of Myristica Fragrans on Fear Behavior in Male Adult Rats of Wistar
}

\author{
M. Dadelahi, G.H. Vaezi and K. Keramati \\ Department of Biology, Islamic Azad University, Dhamghan, Iran
}

\begin{abstract}
Myristica fragrans plant is one of the herbal plants which has medical and cure effects on nerves. By pay attention to the disadvantages of the psychological drugs for body, the researchers want to have a research on the relations between these drugs and fear. In this study, the researchers put extract of Myristica fragrans (50\%) with the $24.53 \%$ humidity is the values of $(600,300.150 \mu \mathrm{g}$ per rat) with six sample that each with the value of $1 \mu \mathrm{L}$. In the control group, they inject 1 micro $\mathrm{L}$ saline to the injection of cerebral ventricular. Also in other positive control group, $20 \mathrm{mg} \mathrm{kg}^{-1}$ Pentylenetetrazol (PTZ) inject to the Intra Peritoneum (IP) after these injections, they evaluate the fear behaviors with the Elevated plus-maze test. The results of this test shows that PTZ is as the positive control group $(\mathrm{p}<0.05)$ can increase the residence time in the close arm more than the saline control group. In comparison, the extract of Myristica fragrans is all doses could increase the specified criteria and decrease the residence time in the open arm. But to the statistical way, two doses $(600,300 \mu \mathrm{g}$ per rat) have the various levels ( $\mathrm{p}<0.05$ ), the saline control group. But when the extract of Myristica fragrans with PTZ was injected to the animal, it reduced the operation of PTZ. In fact, the maximum dose of extract ( $600 \mu \mathrm{g}$ per rat) could show variation to the positive control group PTZ.
\end{abstract}

$\underline{\text { Key words: Fear, injection of cerebral ventricular, elevated plus-maze, Myristica fragrans, coparison, Iran }}$

\section{INTRODUCTION}

The human always was concerned by the illness and pain. So, they find the plants, the best ones. The great men like Zakaria Razi, Abo Ali Sina were the most famous men that knew the plants. By the improvement in sciences such as chemistry, the synthesis of the plants even they could find ways to product artificial plants. It becomes very normal to use the plants for the medical care even, it has been taught at universities. Now-a-days, the researchers use the extract of the plants that changes to the juice or tablets and drugs. Fear is the important reaction to the danger, it includes the autonomic and neuroendocriny reactions and behaviors and of course fear is a physiological defensive response to the damage (Kaplan and Sadock, 1998).

In considerable to the proof of the harmful effect of the hallucinogenic drugs so, we decide to search the negative effect of these drugs. In terms of fear, previous researches showed that Myristica may cause bad headaches, drowsiness, fainting and shaking (Pellow and File, 1986). Myristica can weak Monoamine Oxidase (MAO) inhibitor and it acts as an antioxidant (Sonavane et al., 2002). When someone is influenced by this plant at first of poisonous part. The patient arouse by this drug because of the hallucinogenic, he/she feels hallucination and it causes the arouse of the central nerves system and anticholinerjic (Weil, 2006).

\section{MATERIALS AND METHODS}

To do this research, we use the male adult Wister rats with the weight of $200 \pm 20 \mathrm{~g}$. These rats (weight $120 \mathrm{~g}$ ) are provided from the Razi Institute in Hesarak (Fig. 1). Then, they transfer to the animal protection of Rasoul Akram's University. They protected in special cages for rats on the group of 3-4 numbers. They provide their food (pellet) from Javane laboratory animal company in Mashhad. The rats have enough food, except the time of the test. The physical situation for production of these rats is the lightening, darkness period, $12 \mathrm{~h}$ ( 7 am to $7 \mathrm{pm}$ ) temperature: $22 \pm 2^{\circ} \mathrm{C}$. Laboratory equipment and instruments required for testing are as follows:

- Ohaus scales for weighing rat with a $10 \mathrm{~g}$ accuracy, blade modified to revise the animal hair, a much number of $1 \mathrm{~mL}$ insulin syringes to inject drugs (the number of animals and a number) and accessories described as scissors, scalpel, clamps, forceps, described within etc.

- Gauge 21 syringes, lot of stainless steel for making injection cannula, kulis difficulty 0.5 dirty miter, cutter, papar, lighting study 


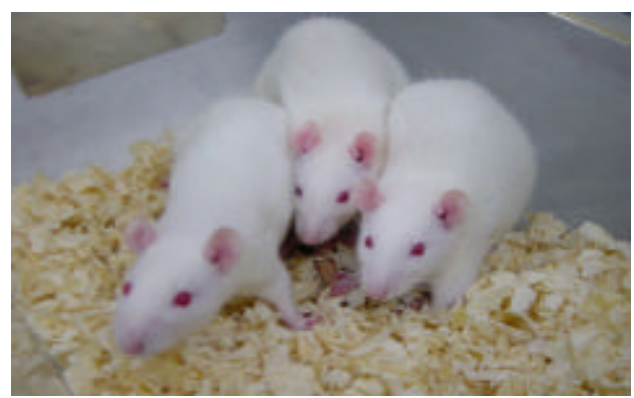

Fig. 1: The samples male adult Wistar rats

- Glasses elegant twist to the large number for dental cement to stabilize and guide cannula on the skull bone, srewdriver for glasses and fine forceps to maintain the desired twist, Dental bit diameter 0.7 and $1 \mathrm{~mm}$ for piercing the skull bone

- Sterile cotton swab and a much-needed, Stoelting stereotaxic apparatus model making America Stoelting Co. Rats using these devices for surgery and ventricular cannula in the area were completely kept constant

- Syringe hamilton made in China with $5 \mu \mathrm{L}$ volume, Dental Gauge 27 srsing cannula for making injections, polyethylene pipe as the interface between hamilton syringes and injection cannulla, Sartorius analytic scales for weighing drugs with 10000 precision of a gram

- Container having a sterile glass doors to provide chemicals and extracts, Rotary machine (to remove the solvent), Buchner funnel, ben Marry

- Elevated plus-maze apparatus made of wood, dgital stop watch three times stopping to measure the rats in each arm Elevated plus-maze apparatus and a set number of hours to make record time, glass or plastic containers to keep the animal brain

Also we have been used the following material and drugs, chetamine $10 \%$ and xylazine $2 \%$ made in Iranian Veterinary drugs companies as anesthesia. Ethanolic extract $50 \%$ of Myristica fragrans seeds, PTZ made in SIGMA Company, USA, available in Nekoazmateb Company located in Tehran Saadat abad, medical alcohol $96 \%$, distilled water, normal saline $(0.9 \%)$, betadine to disinfect surgical site, Dental cement (acrylic powder) and self cooked monomer solution (Marlik Medical Industries) for stabilize a made a guide cannula, chloroform or ether to kill the animal after completion of testing, $10 \%$ formalin for fixation of brain tissue and penicillin 1,200,000 much needed. In this research, PTZ (pentylenetetrazol) made in SIGMA Company is used as anxiogenic and as positive controls. Saline used for control. The extract $50 \%$ of Myristica fragrans is considered as the main material.

Extracting modeling: Myristica fragrans due to being native in India is produced dried. In biosystematics point of view, it has been confirmed by Biosystematics Department of Mashhad, Ferdosi University in terms of genus and species. For extracting Myristica fragrans, soaking it in alcohol $50 \%$ was done. In this model, first measure a certain amount of Myristica fragrans (500 G), mill it then add $400 \mathrm{CC}$ ethanol $50 \%$ and put it in Ban mary in temperature of $30-40^{\circ} \mathrm{C}$ to extract it completely. Once in a while stir the mixture to make extracting easier. Alkaloid found in Myristica fragrans seeds solve in ethanol 50\% well (Nichols and Sanders-Bush, 2001). After complete extraction of alkaloid that is a mixture of ethanol and the seed of the mentioned plant, we smooth the mixture by Buchner funnel, filter study and vacuum pump to eliminate the gross out of the mixture (Demetriades et al., 2005). In this step, we need to eliminate the solvent and make a thick liquid to do this, the mixture is put in Rotary machine in the temperature of $40^{\circ} \mathrm{C}$ and rotation of 60 . Finally, the extract is ready to use.

Surgery and prescription drugs: After the fixation of the animal in stereotaxic device using Packsynus atlas, the coordination of ventricular $\mathrm{AP}=-0.8$ and $\mathrm{ML}=1.6$ from the Bragma area was determined and needle 21 was used as a guide cannula in ventricular. Total 5 days after the surgery in each prescription, the animal receives $1 \mu \mathrm{L}$ of the extract injection in ventricular area by injection cannula no. 27 and hamilton syring.

\section{Experimental groups:}

- Control Group: in this group, male rats receive $1 \mu \mathrm{L}$. of saline via i.c.v.

- Positive control group: in this group, male rats receive $20 \mathrm{mg} \mathrm{kg}^{-1}$ of PTZ via i.p.

- The groups injecting via i.c.v receive $600,300,150 \mu \mathrm{g}$ per rat of the extract

- The groups of having $600,300,150 \mu \mathrm{g}$ per rat of the extract via i.c.v also receive PTZ via i.p. It is important to mention that these groups were 6 $(\mathrm{N}=6)$

Behavioral experiment: Behavioral assessment system for fear is done by elevated plus-maze. This device contains two open arms and two b closed arms, crossing each other in a neutral zone called maze. The closed arms are surrounded by $40 \mathrm{~cm}$ walls (Hosseinzadeh and Sadeghnia, 2007). The size of the open and close corridors is $5 \times 100 \mathrm{~cm}$. The height of the device 


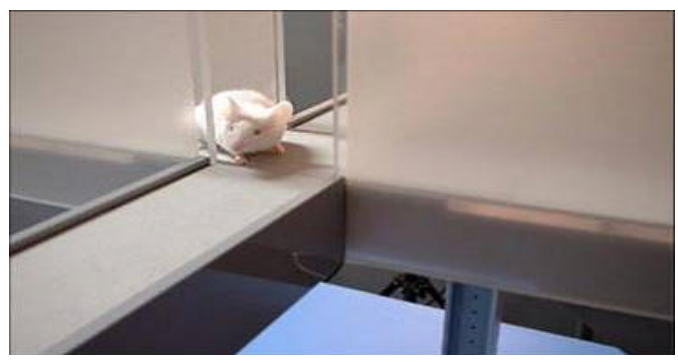

Fig. 2: Elevated plus-mazz

from the floor is $50 \mathrm{~cm}$ and during the experiment there is a light of $100 \mathrm{~V}$ in the height of $120 \mathrm{~cm}$ from the maze in a way that the light is the same in all parts. During the experiment, all the parameters were measured carefully by observation and stopwatch. Entry number and the time spend when the animal is kept in the closed and open corridors is captured as can be shown in Fig. 2.

Histological work: After all the experiments, all brain samples were examined to confirm the correct location of cannula by methilene blue and after 22 days were kept in formalin $10 \%$ and in terms of histological work was examined (Paxinus, 1986). In case of the wrong location of cannula, the sample was eliminated from the experiment (Fig. 3).

Locomotion test: According to this test, displacement of the animal is assessed by statistic analysis using software called SPSS, one way Anova variance and Tukey test in order to assure the animal health during this displacement in each arms. According to paksynus atlas, the coordination is chosen in a way that causes less harm to the brain tissue (Paxinus, 1986). If the location of the cannula is accurate, animal according to locomotion must not be different from other groups. The accuracy of the cannula location was confirmed, too.

Indicators for assessment: After the injection of the mentioned mixture, the animal was kept in a very quiet place for $5 \mathrm{~min}$ and then was put in the middle of the maze facing a closed arm, the light was provided by the $100 \mathrm{~V}$ located above the maze in the height of $120 \mathrm{~cm}$ during the 5 min that the animal was moving around the maze, these parameters were measured:

- $\mathrm{OAE}(\%)$ is the entry number of rats to each open arm

- OAT (\%) is the duration of time that the animal stays in open arm

- $\mathrm{CAE}(\%)$ is the entry number of rats to each open arm

- CAT (\%) is the duration of time that the animal stays in close arm
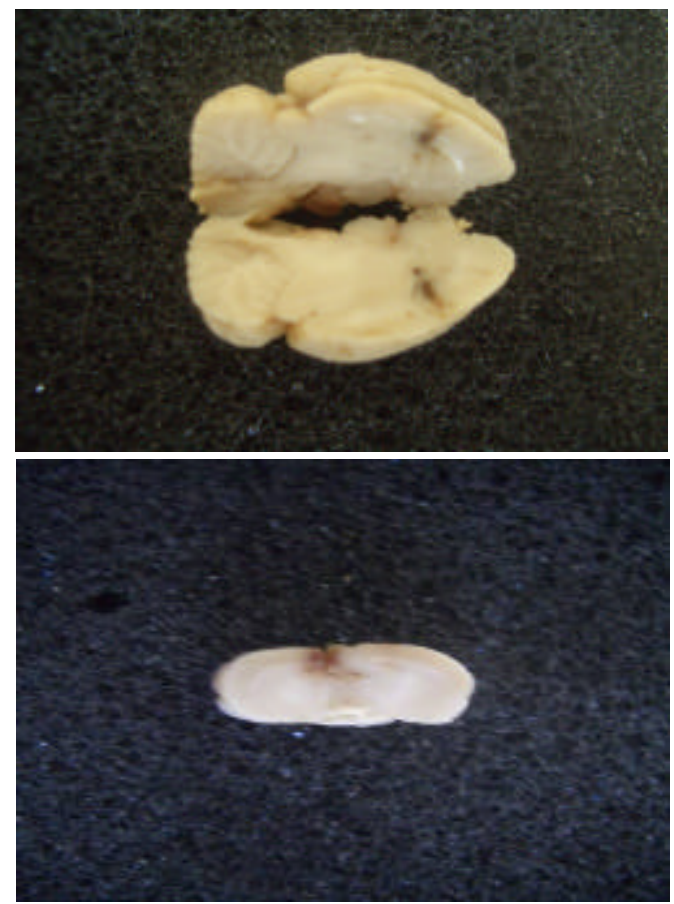

Fig. 3: The cross-section of brain rat

Staying in the close or open arm means when all four legs of the animal is located in the mentioned arm (Hallstrom and Thuvander, 1997). For each animal the percentage of the entrance of the arms and staying duration is calculated in this way. The effect of i.c.v. in Oleander in all experiences using statistic analysis, the SPSS software, one-way anova variance and Tukey test were done and the results were drawn by Excel software. In all cases $(\mathrm{p}<0.05)$ showed a valuable result.

\section{RESULTS}

The process of these statistic achievements via Tukey test and one way anova variance have been shown in Table 1. Comparison of mean and standard deviation percent open arm time in the presence of animals after injection of positive control group (PTZ $20 \mathrm{mg}$ per rat) compared with the control group (saline) has been shown in Fig. 4. In Fig. 4, $N=6, p<0.05$ and unsimilar letters are significantly and the data analyzed by anova one way is shown.

Comparison of mean and standard deviation percentage of time spend of animal experimental group treated with the values 600,300 and $150 \mu \mathrm{g}$ per rat extract nutmeg snooker in the open arm the device Elevated plus-maze compared to control group (saline) and positive control PTZ with Article PTZ $\left(20 \mathrm{mg} \mathrm{kg}^{-1}\right)$ are shown in Fig. 5. In Fig. 5, $n=6, p<0.05$ and unsimilar characters with 
Res. J. Biol. Sci., 5 (10): 656-663, 2010

Table 1: Results of statistic achievements via Tukey test and one way anova variance

\begin{tabular}{|c|c|c|c|c|c|c|c|}
\hline Groups & $\begin{array}{l}\text { Simple } \\
\text { size }\end{array}$ & $\begin{array}{c}1 \text { st } \\
\text { injection }\end{array}$ & $\begin{array}{l}\text { 2nd } \\
\text { injection }\end{array}$ & $\begin{array}{l}\text { OAT (\%) compared } \\
\text { with the control }\end{array}$ & $\begin{array}{l}\mathrm{OAE}(\%) \text { compare } \\
\text { with the control }\end{array}$ & $\begin{array}{l}\text { CAT (\%) compar } \\
\text { with the control }\end{array}$ & $\begin{array}{l}\text { d } \mathrm{CAE}(\%) \text { compared } \\
\text { with the control }\end{array}$ \\
\hline Control & $N=6$ & I.C.V saline $(1 \mu \mathrm{L})$ & - & Normal & Normal & Normal & Normal \\
\hline $\begin{array}{l}\text { Positive } \\
\text { control (PTZ) }\end{array}$ & $N=6$ & I.C.V saline $(1 \mu \mathrm{L})$ & I.P PTZ $20 \mathrm{mg} \mathrm{kg}^{-1}$ & Decrease & Decrease & Increase & Increase \\
\hline $\begin{array}{l}\text { Extract of } \\
\text { Myristica fragrans }\end{array}$ & $N=6$ & I.C.V $600 \mu \mathrm{g} \mu \mathrm{L}^{-1}$ & I.P PTZ $20 \mathrm{mg} \mathrm{kg}^{-1}$ & Decrease & Increase & Increase & Decrease \\
\hline Extract of M.f & $N=6$ & I.C.V $600 \mu \mathrm{g} \mu \mathrm{L}^{-1}$ & - & Decrease & Decrease & Increase & Increase \\
\hline Extract of M.f & $N=6$ & I.C.V $300 \mu \mathrm{g} \mu \mathrm{L}^{-1}$ & I.P PTZ $20 \mathrm{mg} \mathrm{kg}^{-1}$ & Decrease & Decrease & Increase & Increase \\
\hline Extract of M.f & $N=6$ & I.C.V $300 \mu \mathrm{g} \mu \mathrm{L}^{-1}$ & - & Decrease & Decrease & Increase & Increase \\
\hline Extract of M.f & $N=6$ & I.C.V $150 \mu \mathrm{g} \mu \mathrm{L}^{-1}$ & I.P PTZ $20 \mathrm{mg} \mathrm{kg}^{-1}$ & Decrease & Decrease & Increase & Increase \\
\hline Extract of M.f & $N=6$ & I.C.V $150 \mu \mathrm{g} \mu \mathrm{L}^{-1}$ & - & Decrease & Decrease & Increase & Increase \\
\hline Groups & \multicolumn{2}{|r|}{$\begin{array}{l}\text { OAT (\%) compared } \\
\text { with PTZ }\end{array}$} & \multicolumn{2}{|c|}{$\begin{array}{l}\text { OAE (\%) compared } \\
\text { with PTZ }\end{array}$} & \multicolumn{2}{|c|}{$\begin{array}{l}\text { CAT (\%) compared } \\
\text { with PTZ } \\
\end{array}$} & $\begin{array}{c}\text { CAE (\%) compared } \\
\text { with PTZ } \\
\end{array}$ \\
\hline Control & \multicolumn{2}{|r|}{ - } & \multicolumn{2}{|l|}{ - } & \multicolumn{2}{|l|}{ - } & - \\
\hline $\begin{array}{l}\text { Positive } \\
\text { control (PTZ) }\end{array}$ & \multicolumn{2}{|r|}{-} & \multicolumn{2}{|l|}{-} & \multicolumn{2}{|l|}{-} & - \\
\hline $\begin{array}{l}\text { Extract of } \\
\text { Myristica fragrans }\end{array}$ & \multicolumn{2}{|r|}{ Increase } & \multicolumn{2}{|r|}{ Increase } & \multicolumn{2}{|c|}{ Decrease } & Decrease \\
\hline Extract of M.f & \multicolumn{2}{|r|}{ Decrease } & \multicolumn{2}{|c|}{ Increase } & \multicolumn{2}{|c|}{ Decrease } & Decrease \\
\hline Extract of M.f & \multicolumn{2}{|r|}{ Increase } & \multicolumn{2}{|r|}{$\begin{array}{l}\text { Increase } \\
\text { Increase }\end{array}$} & \multicolumn{2}{|c|}{ Decrease } & Decrease \\
\hline Extract of M.f & \multirow{2}{*}{\multicolumn{2}{|c|}{ Decrease }} & \multicolumn{2}{|r|}{ Increase } & \multicolumn{2}{|c|}{ Increase } & Decrease \\
\hline Extract of M.f & \multirow{2}{*}{\multicolumn{2}{|c|}{$\begin{array}{l}\text { Decrease } \\
\text { Increase }\end{array}$}} & \multirow{2}{*}{\multicolumn{2}{|c|}{$\begin{array}{l}\text { Decrease } \\
\text { Increase }\end{array}$}} & \multirow{2}{*}{\multicolumn{2}{|c|}{$\begin{array}{l}\text { Decrease } \\
\text { De }\end{array}$}} & Increase \\
\hline Extract of M.f & & & & & & & Decrease \\
\hline
\end{tabular}

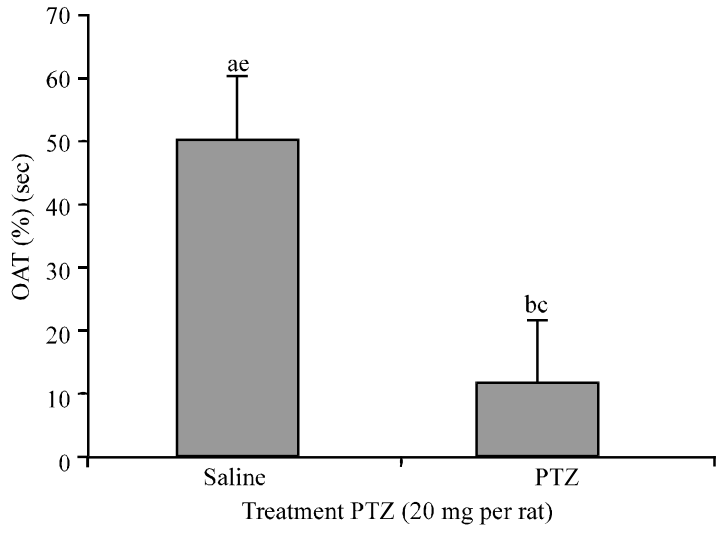

Fig. 4: OAT (\%) vs. negative and positive control

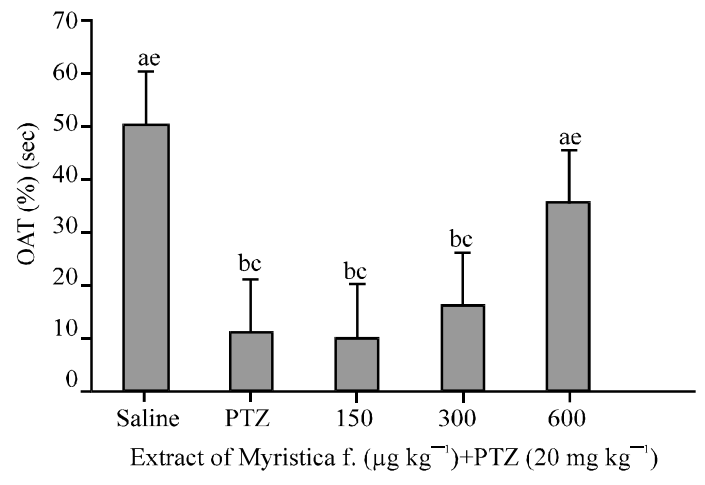

Fig. 5: OAT (\%) vs. extract Myristica f.+PTZ

significant differences by statistical analysis and data one way Anova is shown. Comparison of mean and standard deviation percent of entry number of animal

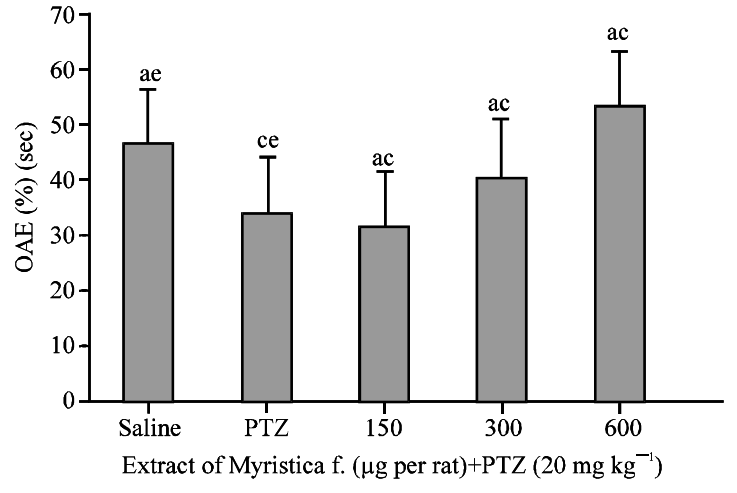

Fig. 6: $\mathrm{OAE}(\%)$ vs. extract Myristica f. $+\mathrm{PTZ}$

experimental group treated with the values 600,300 and $150 \mu \mathrm{g}$ per rat extract nutmeg snooker in the open arm, the device elevated plus-maze compared to control group (saline) and positive control PTZ with Article PTZ $\left(20 \mathrm{mg} \mathrm{kg}^{-1}\right)$ are shown in Fig. 6.

In Fig. $6, n=6, p<0.05$ and unsimilar characters with significant differences by statistical analysis and data anova one-way is shown. Comparison of mean and SD percent of time spend of animal experimental group treated with the values 600,300 and $150 \mu \mathrm{g}$ per rat extract nutmeg snooker in the close arm elevated plus-maze compared to control group (saline) and positive control PTZ with Article PTZ $\left(20 \mathrm{mg} \mathrm{kg}^{-1}\right)$ are shown in Fig. 7. In Fig. $7, \mathrm{n}=6, \mathrm{p}<0.05$ and unsimilar characters with significant differences by statistical analysis and data anova one-way is shown. Comparison of mean and standard deviation percent of entry number of animal 


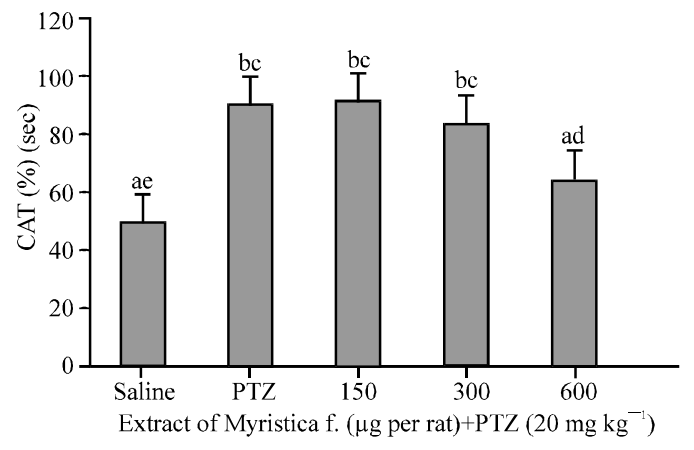

Fig. 7: CAT (\%) vs. extract Myristica f.+PTZ

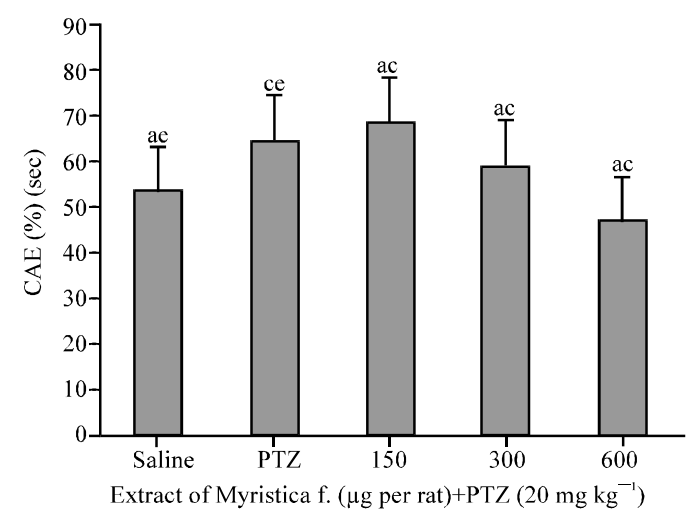

Fig. 8: $\mathrm{CAE}(\%)$ vs. extract Myristica f. $+\mathrm{PTZ}$

experimental group treated with the values 600,300 and $150 \mu \mathrm{g}$ per rat extract nutmeg snooker in the close arm Elevated plus-maze compared to control group (saline) and positive control PTZ with Article PTZ $\left(20 \mathrm{mg} \mathrm{kg}^{-1}\right)$ have been shown in Fig. 8.

In Fig. $8, \mathrm{n}=6, \mathrm{p}<0.05$ and non-homologous characters with significant differences by statistical analysis and data one way anova is shown.

Comparison of mean and SD percente of time spend of animal experimental group treated with the values 600 , 300 and $150 \mu \mathrm{g}$ per rat extract nutmeg snooker in the open arm, the device elevated plus-maze compared to control group (saline) and positive control PTZ without PTZ $\left(20 \mathrm{mg} \mathrm{kg}^{-1}\right)$ have been shown in Fig. 9. In Fig. 9, $\mathrm{n}=6$, $\mathrm{p}<0.05$ and non-homologous characters with significant differences by statistical analysis and data one way anova is shown.

Comparison of mean and standard deviation percent of entry number of animal experimental group treated with the values 600,300 and $150 \mu \mathrm{g}$ per rat extract nutmeg snooker in the open arm the device elevated plus-maze compared to control group (saline) and positive control PTZ without PTZ $\left(20 \mathrm{mg} \mathrm{kg}^{-1}\right)$ have been shown in Fig. 10. In Fig. 10, $\mathrm{n}=6, \mathrm{p}<0.05$ and non-homologous characters with significant differences by statistical

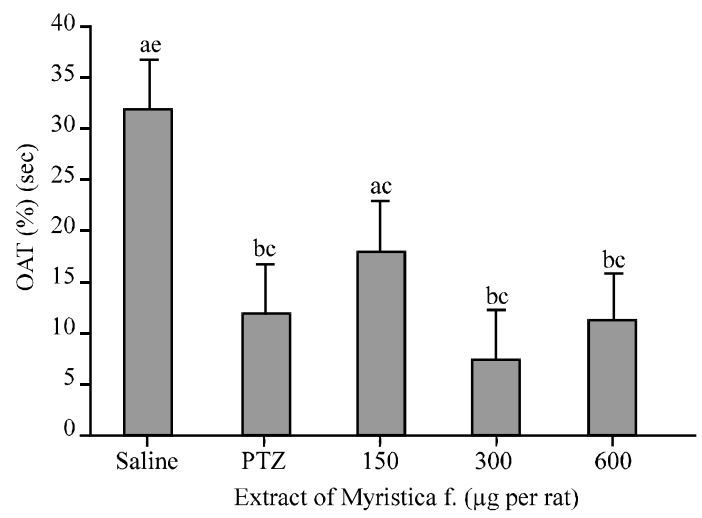

Fig. 9: OAT (\%) vs. extract Myristica f.

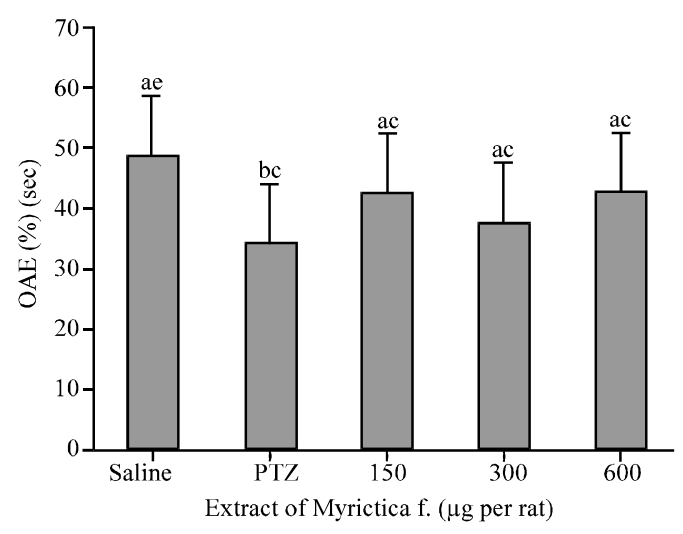

Fig. 10: OAE (\%) vs. extract Myristica f.

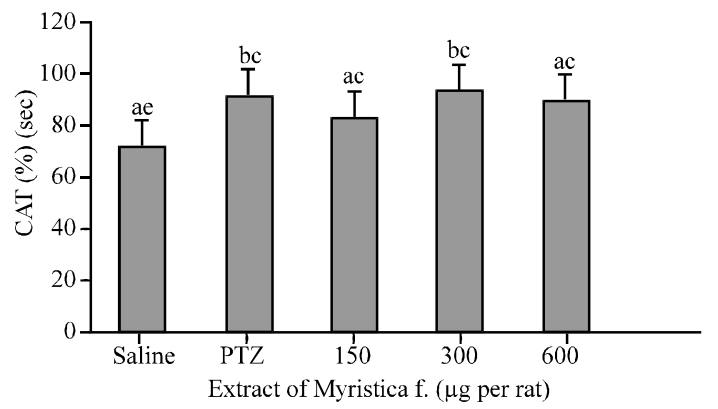

Fig. 11: CAT (\%) vs. extract Myristica f.

analysis and data one way Anova is shown. Comparison of mean and SD percente of time spend of animal experimental group treated with the values 600,300 and $150 \mu \mathrm{g}$ per rat extract nutmeg snooker in the close arm elevated plus-maze compared to control group (saline) and positive control PTZ without PTZ $\left(20 \mathrm{mg} \mathrm{kg}^{-1}\right)$ have been shown in Fig. 11. In Fig. 11, n = 6, p<0.05 and non-homologous characters with significant differences by statistical analysis and data one way anova is shown. Comparison of mean and standard deviation percent of 


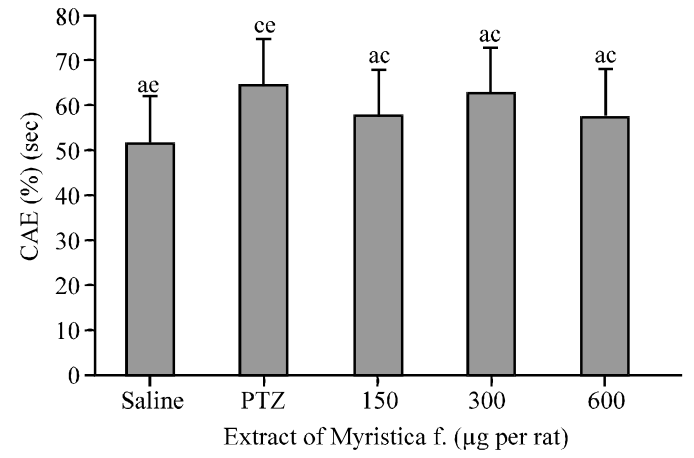

Fig. 12: $\mathrm{CAE}(\%)$ vs. extract Myristica f.

entry number of animal experimental group treated with the values 600,300 and $150 \mu \mathrm{g}$ per rat extract nutmeg snooker in the close arm Elevated plus-maze compared to control group (saline) and positive control PTZ without PTZ (20 $\left.\mathrm{mg} \mathrm{kg}^{-1}\right)$ have been shown in Fig. 12. In Fig. 12, $\mathrm{n}=6, \mathrm{p}<0.05$ and non-homologous characters with significant differences by statistical analysis and data anova one-way is shown.

\section{DISCUSSION}

The cause of this affection is influenced by the compounds and mechanisms some of the most effective compounds in this branch are some of the alkaloid that can pass from the black of cerebrospiral blood. Two of the most important alkaloids that exist in Myristica fragrans are Myristicine and Trymiristine (Hallstrom and Thuvander, 1997). The researches on this plant (Myristica fragrans) show that Myrisricine can cause provoking effects on central nerve system. It is a hallucination drug and can weak Monoamino Oxidase (MAO) inhibitor and it acts as an antioxidant and its' structure is similar to serotonin agonists. Based on the researches, the reaction of Myristica fragrans and diazepam drugs or Buspiron had seen on rats, also eating Myristica fragrans and flunitrazepame simultaneously could cause death. These alkaloids may metabolize one structure like Amphtamine by the effect of hallucinogen like LSD.

To cure the patient, the hallucino can use to converse the effect of amphtime like thing (Demetriades et al., 2005). In this research, the extract of Myristica fragrans includes compounds of alkoloid Myristicine and Trymiristine. To study the fear behavior, this drug with the doses of (600, 300 and $150 \mu \mathrm{g}$ per rat) by the method of i.c.v with the PTZ drug in the feature of I.P and without this drug (PTZ) inject to the animal $(n=6)$. The research has been done in two steps. Step one the various values from the extract of the Myristica fragrans with PTZ in the form of I.P simultaneously and the next step to complete the research the same value of the extract from the 1st step without PTZ is studied because they want to study the effect of the extract alone and compare it with the previous results. To obtained results, the noticed extract without PTZ can instigation anxiety and decreases the percent of time of the animal spend in the open arm to the comparison to saline and statistically, the doses of the extract (600 and $300 \mu \mathrm{g}$ per rat) have the meaningful variation $(\mathrm{p}<0.05)$ with the control group.

As it has shown in Fig. 12, two noticed doses reduced the percentage of the time of the presence in the open arm in comparison with the positive control group (PTZ) but it was not meaningful and the presence of the numbers of the entrance to the open arm in all doses is reduced in comparison to the control group (saline) too but it could not act like the power of PTZ in fact it is in the middle of the positive and negative control group.

These results statistically were not meaningful but these results complete the others. In the percentage of time of the presence of the extract in close arm in all doses could increase the time in comparison to the control group (saline) therefore statistically, the middle dose $300 \mu \mathrm{g}$ per rat could prove this. In comparison to the positive control group (PTZ), the doses (600, 300 and $150 \mu \mathrm{g}$ per rat) act like PTZ but the least dose ( $150 \mu \mathrm{g}$ per rat) in this criteria in comparison to the positive control group shows the reduction and becomes between two positive and negative control groups. Based on the results, all doses of extract could increase the percentage of numbers entrance to close arm in comparison to the control group (saline) but statistically this increase is not meaningful and also these doses can show reduction in comparison to the positive control group and become between two positive and negative control groups.

The results of the other step of the research that include the extract of Myristica fragrans with the PTZ show that the percentage of the time of the presence in the open arm in all doses was decreased in comparison to the control group (saline) in fact the doses of (300 and 150 $\mu \mathrm{g}$ per rat) the expressed statistically are proved these results too and show the meaningful variation to the control group but in comparison to the positive control group (PTZ), the doses 600 and $300 \mu \mathrm{g}$ per rat could increase this time but the less dose (150 $\mu \mathrm{g}$ per rat) could not do this and act like this drug and statistically the greatest dose ( $600 \mu \mathrm{g}$ per rat) could show the increase of time in presence in open arm and have the meaningful level $(\mathrm{p}<0.05)$ in comparison to the positive control group.

By considering the statistical results, there is a meaningful variation between the most and the less doses $600-150 \mu \mathrm{g}$ per rat that shows the dose dependende to cause the effects. Of course, about the number of 
entrance criteria to the open arm $(\mathrm{OAE} \%)$, the greater dose, $600 \mu \mathrm{g}$ per rat and dose, $300 \mu \mathrm{g}$ per rat shows the increase in the number of entrance to the open arm in comparison to the both control groups and could cause the reduction in the PTZ effects but $150 \mu \mathrm{g}$ per rat dose could not confront with this material and the results show the value of the expressed in the plant and it is completely dose dependend.

The percentage of the time of the presence in the closed arm (CAT\%) in all doses cause increase in comparison to the saline control group and statistically, the doses (300-150 $\mu \mathrm{g}$ per rat) have proved this result and have a meaningful variation to the control group but show reduction in comparison to the positive control group and reduce the $\mathrm{PTZ}$ effect. This reduction is related to the extract of the plant. Because the greatest dose $(600 \mu \mathrm{g}$ per rat) has the meaningful variation $(\mathrm{p}<0.05)$. It must be noticed that statistically, there is variation between the less and the most doses $(600-150 \mu \mathrm{g}$ per rat) that shows the dose dependende to cause the effects.

By considering the percentage of the numbers of entrance to the close arm (CAE\%), the greatest dose ( $600 \mu \mathrm{g}$ per rat) shows the reduction for the number of entrance to the closed arm in comparison to the both control groups and cause reduction about the PTZ effects. The dose ( $300 \mu$ g per rat) causes reduction for this criteria in comparison to the positive control group and reduces the $\mathrm{PTZ}$ effect but the dose $(150 \mu \mathrm{g}$ per rat) could not confront with this material and the results show the value of the extract and it is completely dose depended. In fact, statistically the greatest dose of the extract could have a meaningful variation $(p<0.05)$ with the PTZ and reduces the PTZ effects. It is important to consider that in this step, all doses had received the PTZ simultaneously, results show that in comparison to the 1st step that showed the increase of anxiety this step shows the reaction between these two materials.

Anxiety showed property creation but in the 2nd stage with an anxiety-causing substance was used to simultaneously, consider the effects of reduced material and show the interaction between the brain systems involved in visitors. Based on studies, Pentylenetetrazole (PTZ) drug at a specific dose (20 $\mathrm{mg}$ per rat) is a property anxiogenic that this trend in the study and also statistically significant as was proven (Hosseinzadeh and Sadeghnia, 2007). As we know GABA is a neurotransmitter inhibitory through by activating chloride channels decreases neuronal activity. PTZ increased permeability and flow of potassium ion in the membrane including $\mathrm{Na}$ and $\mathrm{Ca}$ membrane excitability of neurons. Also, this chemical increases extracellular glutamate and aspartate levels in the amygdala and the frontal cortex and be synaptic glutamate removal ability is reduced by PTZ. PTZ as a (GABA A) receptor antagonist through connection for connecting positions picrotoxin caused blocking of GABA receptors and through involve GABAerjic system creates fear in animals. Also, important material impact PTZ-hormone corticosterone mediate effects of anxiety, it is creation.

As we know, electrical stimulation of amygdala increases plasma corticosterone levels probably a result of HPA axis is the amygdala. Serotonergic system in the brain stimulates fear and anxiety is important (Nichols and Sanders-Bush, 2001).

As noted, one of safrol alkaloid compounds in the extract is available, acted like serotonin agonist and serotonin-like effects have increased concentrations of serotonin through serotonin reuptake inhibition and probably through the serotonergic system involved in creating fear behavior is involved.

The other hand, studies have shown that the similarity of building molecular alkalid Myristicine and Trymiristine with combining serotonin can many of these compounds to bind to receptors serotonergic justify that probably as a composition competition for occupied positions of operation with serotonin to compete.

The characteristics of plants like Myristica snooker being the mono-amino oxides as research has shown that serotonin and noradrenaline increases act MAO. In this study, Myristica extract without PTZ on fear behavior in animals was shown. Probably also be dose dependent. $\mathrm{p}<0.05$ and the creation of anxiety effect was proven. However, this extract administered with PTZ administration caused an interaction (interaction) between the two were combined. And showed reduced function PTZ. Probably due to the interaction of two serotonerjic system and is GABAerjic. Research conducted has shown that several compounds such as those compounds due to receptor $5 \mathrm{HT}$ (1A) and 5HT3 and NMDA and GLY can act stimulatory effects of $\mathrm{PTZ}$ to reduce substance.

As mentioned compounds in the extract of Myristica is like agonist serotonin acts and according to the results of this study, probably receptor agonist $5 \mathrm{HT}(1 \mathrm{~A})$ and 5 HT3 has been through the involvement of these receptors, the effects of this chemical compound reduce effect of anxiety creation caused by PTZ.

\section{CONCLUSION}

Finally, it was concluded that probably, the noticed extract could cause the fear action and the fear depends on the doses of the extract but when recommended with 
the PTZ simultaneously, reduced the PTZ operation. It may be was interaction between of the serotonerjic and GABAergic systems in brain and they reduced the effect of each other.

\section{ACKNOWLEDGEMENT}

The researchers wish to thanks Prof. Hadi Arabshahi from Ferdowsi University of Mashhad for his support of writing up the study.

\section{REFERENCES}

Demetriades, A.K., P.D. Wallman, A. McGuiness and M.C. Gavalas, 2005. Low cost, high risk: Accidental nutmeg intoxication. Emerg. Med. J., 22: 223-225.

Hallstrom, H. and A. Thuvander, 1997. Toxicological evaluation of myristicin. Nat. Toxins, 5: 186-192.

Hosseinzadeh, H. and H.R. Sadeghnia, 2007. Protective effect of safranal on pentylenetetrazol-induced seizures in the rat: Involvement of GABAergic and opioids systems. Phytomedicine, 14: 256-262.
Kaplan, H.I., and B.J. Sadock, 1998. Kaplan and Sadock's Synopsis of Psychiatry: Behavioral Sciences, Clinical Psychiatry. 8th Edn., Lippincott Williams and Wilkins, London, ISBN-13: 978-0683303308, pp: 1401.

Nichols, C.D. and E. Sanders-Bush, 2001. Serotonin receptor signaling and hallucinogenic drug action. Heffter Rev. Psychedelic Res., 2: 73-79.

Paxinus, P.Z., 1986. Atlas of Paxins. Jhon Willey and Sons, New York.

Pellow, S. and S.E. File, 1986. Anxiolytic and anxiogenic drug effects on exploratory activity in an elevated plus-maze: A novel test of anxiety in the rat. Pharmacol. Biochem. Behav., 24: 525-529.

Sonavane, G.S., R.C. Palekar, V.S. Kasture and S.B. Kasture, 2002. Anticonvulsant and behavioural actions of Myristica fragrans seeds. Indian $\mathrm{J}$. Pharmacol., 34: 332-338.

Weil, A.T., 2006. The Use of Nutmeg as a Psychotropic Agent. Harvard Medical School Publications, Boston, Massachusetts. 